\title{
QUANTUM EXISTENCE OF PARALLEL WORLDS: COMPARATIVE ANALYSIS OF PHOTONS WITH DERIVATIVES OF HOLY SCRIPTURES
}

\author{
Kashif Masood Sethi ${ }^{1}$ and Fareeha Zafar ${ }^{2^{*}}$ \\ ${ }^{1}$ HUM Network / Research Scientist, Government College University, Lahore, Department of \\ Computer Science, Kashifsethi@hotmail.com \\ ${ }^{2}$ Prof. Dr, Government College University, Lahore, Department of Computer Science, Pakistan, \\ dr.f.zafar@gcu.edu.pk \\ ${ }^{*}$ Corresponding author
}

\begin{abstract}
This paper presents scientific reasoning as well as mapping of the concept of Angels to its derived and illustrated meaning of "Light" or "Noor" which in Arabic and in Hebrew refers to body of light in its original meaning. The author in view of illustrated meanings collected from secondary resources and scriptures, has tried to map features of light with those of known characteristics of angels and has derived conclusion on the scientific existence of quantum intranet and internet in infinite phase of time. The Research also highlights the existence of data in quantum waves encapsulated in the infinite loop of time that carries information about every living being existed in world. The paper explains the connectivity between photons to photons, and photons to all other waves within electromagnetic spectrum which is equally mapped over angels to angels and angels to man and other objects in order to compile the concept of angels as information carrier and to keep log of every action and deed. It is also derived that whether or not existence of living creations is over in this world, the data stays in loop of infinity and is catch able out of phases of time. Investigated studies and comparison are made on nature, behaviour, movement, availability, data encapsulation as well as data transmission within photons and derivatives are clearly pointing to the concept of quantum infinity. The recent discovery of gravitational waves by MIT which were resulted after the collisions of black holes and explosive deaths of stars are taken as case study. It is also concluded that logical reasoning of Internet of things and quantum physics strongly exist on common grounds behind the religious faiths based on holy books around the world.
\end{abstract}

\section{INTRODUCTION}

The research attempts to provide a unified overview of the broad field of Communication and existence of universal Data by relating it to various forms of data carriers. People from centuries have been receiving guidance to reform their lives and behaviour around the phenomenal faiths presented in Holy Scriptures.

The organization of this paper reflects an attempt to break this massive subject into comprehensible parts 
and to build a state of art reasoning, which is uniformly supported by sciences as well as by secondary data narrated from scriptures. The paper is intended to invite science community to investigate the concepts of quantum physics and map them with the scriptures which were given to mankind since the birth of times.

The following basic theme serves to unify the discussion.

1. Principles: There are number of principles which are narrated in Holy Scriptures in Arabic, Hebrew and are narrated in Bible. The concept of Angels, their interaction, behaviours and their responsibilities is discussed

2. Standards: Standards are assumed to have an increasingly dominant role in the field of scientific communication. An understanding of current Quantum logistics, Electromagnetic Spectrum, Data and its behaviours, Anatomy of electromagnetic Waves, and Gravitational Theory.

3. Philosophy of information: Philosophy of information not only provides a fresh look at traditional scientific problems but also allows investigating genuinely new philosophical problems based on interdisciplinary technological fields of subjects. Author has presented comparative analysis of Modern sciences with scriptures and invited logical reasons to believe, what we have been accepting by sciences or by books around the world.

\section{QUANTUM MECHANICS}

Quantum is discrete unit of any particular quantity. Newton's physics laws suggest that particles may have momentum while light have frequency.

Figure 1: shows that the atom is consisting of nucleus at its centre, which is consists of positively charged proton and neutral charged neutron. While, negative charge particle 'electron' revolve around nucleus which is tightly bound to nucleus by electromagnetic force. Bohr postulate that classical theory of radiation does not exist for atomic scheme. Bohr's has three basic postulates:

1. Electron can revolve in certain stable orbit around the nucleus of atom without emission of energy in the form of radiation.

2. Radiation is emitted by the atom when electron will jump from higher energy's orbit to lower energy's orbit or energy is absorbed when electron jumps from lower to higher energy level (orbit).

3. Electron's orbital angular momentum is $L$ which revolve around the nucleus is integral multiple of $h / 2 \pi$, where $h$ is plank's constant $L n=m v n r n=n h / 2 \pi$. $m$ represents electron mass, $v n$ is the velocity of $n$-orbit of radius $\mathrm{rn}$ and $\mathrm{n}$ represents the integer number (Marín, E. 2008).

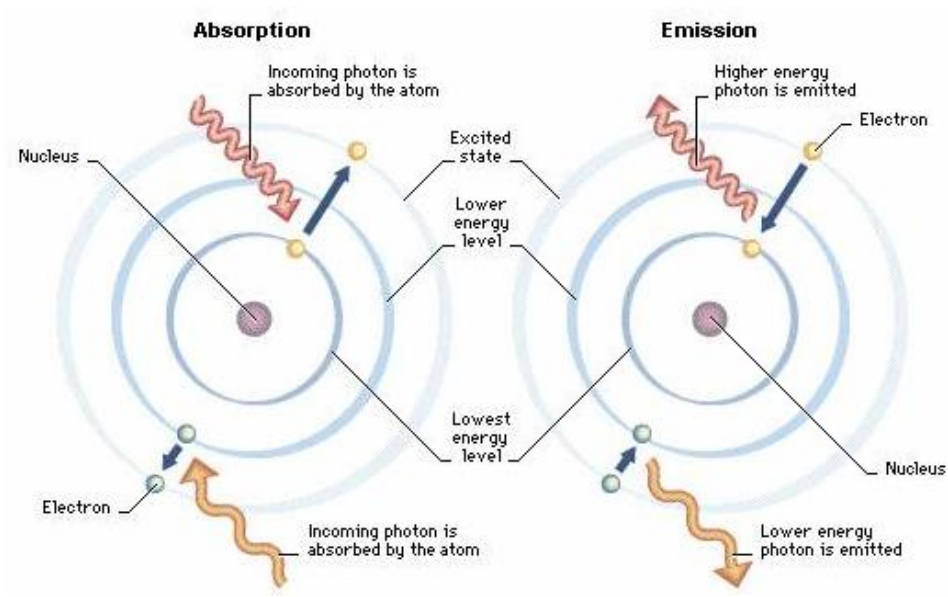

Fig1: Behaviour of photon (Marín, E. 2008)

Thus Quanta refers to a discrete packet of energy, charge or any other measure. Exchanges in energies happen in discrete quantity. For illustration, when some material absorbs light, this doesn't refer that energy level in that material has raised, however it starts representing discrete jumps. On other instance, when material absorbs light quanta, the energy level (orbit) of an electron within an atom does not possess some continuous range of energies, but it has discrete orbits. This concept leads to the wave -particle duality. In Wave-particle duality, every elementary particle or quanta entity may be partly described in terms not only of particles, but also of waves. Particles are described by wave function behaviours and particles are also interacted at specific points similar to particles. Plank's constant was introduced to strengthen this, which is 
represented by "h=6.626*10-34 J.s". This constant value help to relate wave-like quantity mapped with 'particles' like quantity. Energy and matter behaviour on the earth are described by Einstein's theory of relativity and quantum theory (Hoffmann, D. (2009). pp. 478-480). Six basics concepts are relevant to the quantum.

1. Quantum describes everything in this universe is made of wave nature and particles at the same time;

2. Quantum is considered to be discrete

3. Quantum is probabilistic which refers that for a physicist envisages experimental studies, his prediction is based on probabilities.

4. Quantum physic is limited to the scale of atoms and small particles

5. Quantum physics is controlled by mathematical model and rules. (Tantor Audio, 2011)

Quantum changes and becomes another quantum, the change and resolution goes towards infinity. Quantum is everlasting production of infinite which is it is not acquired beyond quantum. This 'beyondQuantum' is the conceptual instant of nonexistence of quantum, disappearance of quantum from this point represent quantum own act; so "beyond Quantum" is related to its infinity.

However, quantum remain continuous to its beyond; quantum consists of individual other of itself, mean external to itself; this externality is none other, but quantum itself. Being infinite is also a quantum. The continuity of this quantum to other and beyond the infinity produces the conjunction of both small and great infinity. (Tantor Audio, 2011)

Quantum theory of light describes wave-particle and nature of light. Light consists of photon while matter is composed of electron, neutron and proton.( J. Ko, I.-Y. K.-T.-Y, 2016)

\section{OPTICAL COMMUNICATION}

It is essential to understand that optical communications is different from electronic communications. It is considered that light flow in a fibre similar to the flow of electricity in a wire which is false concept. Light is considered electromagnetic wave while optical fibre is waveguide.

\subsection{Optical Transmission System}

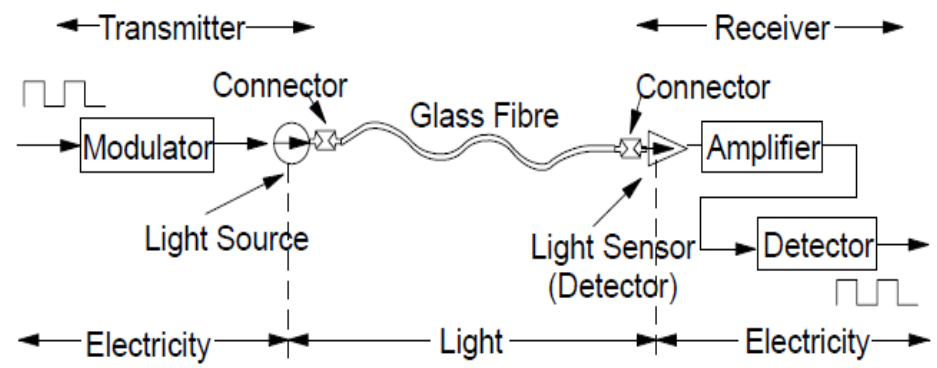

Figure2. Schematics of Optical Transmission. (Dutton, H. J., 1998).

The Figure 2, above, shows schematics of Optical transmission. A bit stream is passed through a modulator, in the form of electrical pulse. The data is encoded to light source i-e, laser, or Light Emitting Diode and fibre is used for the transfer of light.

- When light flow down to fibre, due to time association, it experienced scattering and loss of power.

- At the receiver end of fibre, light is entered to detector and it is then transformed into electrical type.

- Signal amplification is done and send to a different detector, which separate each state and change its timing. Then, sequence of each state is decoded, resulting into reconstruction of the unique bit stream. (Dutton, H. J., 1998).

\subsubsection{Co-relation with Scriptures}

When God wants to interact with his creations including humans, He used certain methods. This procedure of interaction is done via Angels. Angels are only carriers; They safeguard the data. As narrated in Scripture: 
"Allah chooses messengers from angels and from men for Allah is He Who hears and sees (all things)".

(Surah Al-Hajj, 75)

\section{THE NATURE OF LIGHT: LIGHT AS A PARTICLE}

These light "things" have energy that depends on the wavelength. With the emergence of Planck's constant and using photon model, it is a known concept that a brighter light produces more photons per second. (Marín, E. 2008). Maxwell's equations prove, that light is a wave (Huray, P. G.,2009)

\subsection{Light Interference: Young's Experiments}

The ray model of light works fine when the distances involved between source and destination is many times larger than the wavelength. Thomas Young in 1802, presented pattern "interference fringes" of dark.
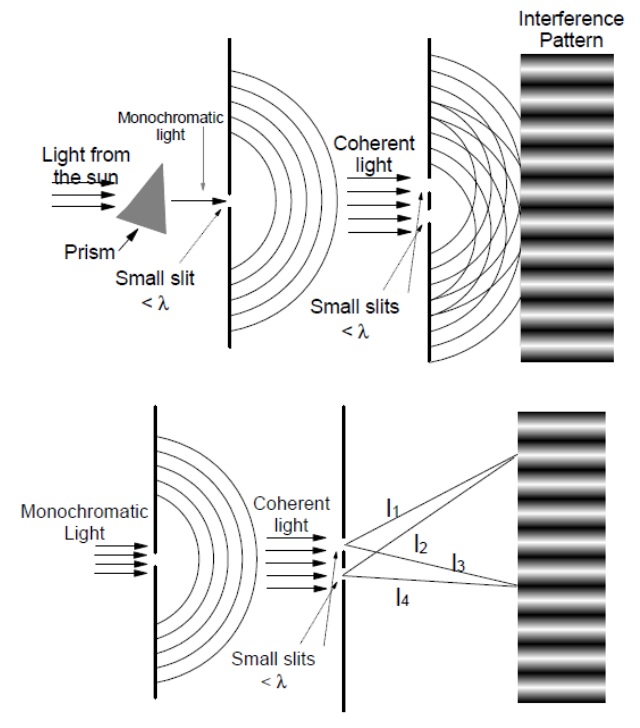

Fig:3 Interference Effects.( Huray, P. G.,2009)

Figure 3. Shows Light and dark line of pattern is appeared due to different distance travel by light between two slits. In the given phase, enlightening light between two slit is coherent, when electric field vectors of wave in phase then waves strengthen one another on the screen, otherwise they cancel the effect of each other. Thu, if the distance of travelled wave is multiple of wavelength, resulting in strengthening and constructive interference is obtained. When the difference of travelled wave is an odd multiple of halfwavelengths such as $\mathrm{I}^{3}$ and $\mathrm{I}^{\prime}$ in figure, waves cancel the effect of each other and dark band is obtained on the screen. The power of wave has been transferred from the dark bands to the bright band. The whole power of optical planned on the screen; it will remain same without any loss. Thus, Energy is conserved and persuasive confirmation for light behaves like wave.

\section{QUANTUM MECHANICS}

Whether or not Light is wave or particle, Scientifically finding existence of Light is another query. Schrodinger's equation is given below where $\Psi$ is the wave function. Which helps get the probability density, or description of where a "photon' particle is supposed to be found.

$$
i \hbar \frac{\partial}{\partial t} \Psi(r, t)=\left[\frac{-\hbar^{2}}{2 m} \nabla^{2}+V(r, t)\right] \Psi(r, t)
$$

Photons, find them in dark, and you can find them in Light. The absence of Light is dark, but Young's experiments proved that when intensity of light is extremely low in aforementioned Young's experiment, photons were spaced at a extended time separately (second), then there could be no concept of wave interference. But the effect of interference still took place. Which means that photon passes through both slits.. 


\subsection{Co-relation with Scriptures:}

Scriptures define Angels as 'Light', but scriptures also define working of 'Angels 'during all the times, whether its day light or at night. If we take grammatical and English illustration of Seen-light, the author may wrongly conclude that Angels being "Light" are send during day and at night when the sun sets; there are no angels, which would be ridicule in itself. Another Question arise here, that if absence of Light is Dark, can we not have "Angels" when its all dark around? In order to respond this query, we need understand few basic things:

1- Angels are narrated as Light, but all light produced is not angels

2- Angels have properties, which are that of Light. Man produced Light can act as carrier wave and hence cannot be Angel in its term of Messenger

3- It is further more important to understand that Scriptures narrate Angel as, data carrier which travels at speed of light making it i-e unseen; A light that is send as messenger from skies to earth and it travels with a speed so fast, making it unseen and also this light stays in between skies and earth.

4- Angels in form of light, record data and keeps it safe until infinity.

Scriptures says,

"... For in the presence of your Lord are those who celebrate His praises by night and by day. And they never flag (nor feel themselves above it)." (Quran 41:38)

And also

......"They celebrate His praises night and day, nor do they ever slacken." (Quran 21:20)

In order to prove that Angel is light and they traverse at speed of light, a very interesting verse from a Scriptures resolves this phenomenon.

"(Allah) Rules the cosmic affair from the heavens to the Earth. Then this affair travels to Him a distance in one day, at a measure of one thousand years of what you count" (Quran 32.5)

Scientifically Moon takes one round around earth in its orbit and travels $2152612.27 \mathrm{~km}$ in one month, having said that, distance covered in an year $2152612.27 \times 12$ i-e $25831347 \mathrm{~km}$

A thousand years shall be $25831347 \times 1000 \mathrm{i}-\mathrm{e}=25831347000 \mathrm{~km}$ which is distance,

One earth day equals 24 hours and in seconds it makes 86164 seconds as time,

If author tries to calculate Speed narrated in scripture and correlates it with philosophy of science it will be break down in given steps:

Step 1) Formula: Speed $=$ distance $\div$ time

Step 2) Cosmic Speed $=25831347000 \div 86164$

$=299792 \mathrm{~km} \backslash$ second which is exactly the speed of the light.

Thus a scripture i.e.- Quran has mentioned some 1400 years ago about "speed of light" in a well conclusive way, the scripture also narrated, that messages travel to Lord of cosmic affairs of earth and heaven at the Speed of Light. Science today has evidences, that data can be transferred at highest of its speed in the form of light. This same reasoning from scripture also supports section 5.3 below, where science says that light can travels from Space to earth and vice versa

\subsection{Electromagnetic Waves}

Light consists of tiny particles called "photons" or "corpuscles".(" Einstein for membership in the Royal Prussian Academy of Science-Theory of Quanta",2016)

When single photon force out position of an electron, photon transfer all of its energy to the electron. Greater 
intensity means large amount of photons but energy of each photon is considered to be same.

\subsection{Light travel from Space to earth}

Light speed is same for all inertial frames. (Koks., 2014)

- The motion of observer and speed of light are independent to each other.

-The speed of light is independent with time or place.

- In 1879, it was observed that light must need medium for propagation in space, the ether. Michelson and Morley were two scientists who set up an experiment to identify the ether; they observed relative change in the speed of light as Earth changed its direction relative to the sun during the year. They were astonished; they did not identify any change in speed of light.

\section{QUANTUM INTRANET: SCIENCE}

In (Davies, Kenneth, 1990), radio waves are light waves. Similarly, Infrared radiation (IR), UV, X-rays and gamma rays are all kind of light waves. The main distinction between these and other kinds of light (visible light) is the wavelength of light. The energy carried by a radio wave is low, while the energy carried by a gamma ray is high.

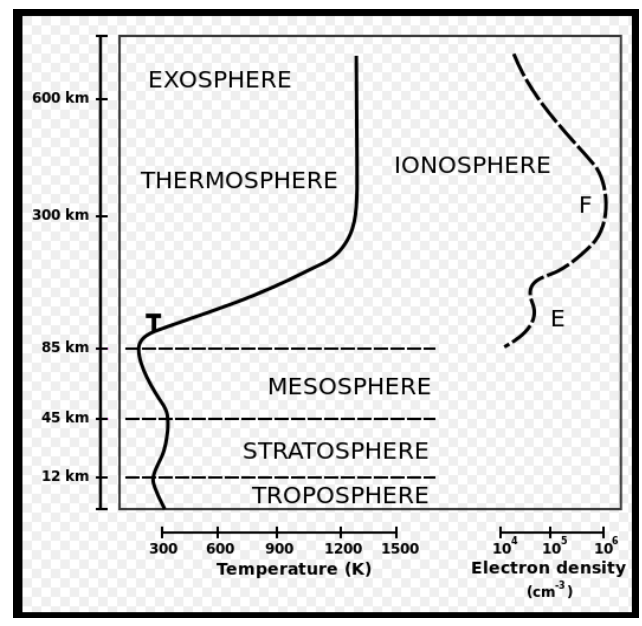

Fig:4 five layers of atmosphere (Davies, Kenneth,1990),

The diagram above represents a scientific narration of existence of light in its various forms around the earth. It is understandable that light like particles are surrounded, while varying at distance from earth in form of Troposphere which is until $12 \mathrm{Km}$ to the terrestrial surface of earth and beyond which is Stratosphere which ranges until $45 \mathrm{~km}$. After this range Mesosphere exists until $85 \mathrm{Km}$ from surface of earth and then Thermosphere and Exosphere which are jointly called lonosphere with density of electrons ranging from 104 till 106 per $\mathrm{cm}-3$.

\subsection{Co-relation with Scriptures}

Philosophy of information narrates this existence with that of Angels and relates the density with distribution of Power between them.

Different scripture depicts existence of this creature and its fast speed travel between earth and space. We conduct this research to know about some hidden reality of this world.

Torah narrates about four different angels as:

"May the angels of God protect you:

Michael - the messenger of God

Gabriel - the strength of God

Raphael - the healing power of God

Uriel - the light of God

Thus Angels carry high Power as well as low Power for the purpose of various operational activities 
(Introduction to faith of Islam, 2016)

\section{PHOTON TO PHOTON COMMUNICATION: DATA COMMUNICATION IN ELECTROMAGNETIC SPECTRUM}

This section discusses Data Exchange between Photons, Quanta and Electromagnetic Waves. When electron propagated in free space or wired, it creates electromagnetic waves. Electromagnetic waves are concerned with electrical as well as magnetically behaviour. Thus, signals are definite electromagnetic waves or voltage which travels in guided or unguided media. Data communication of electromagnetic signal either in digital or analogue transmission. Only wide range of frequency within electromagnetic spectrum is used in data communication,

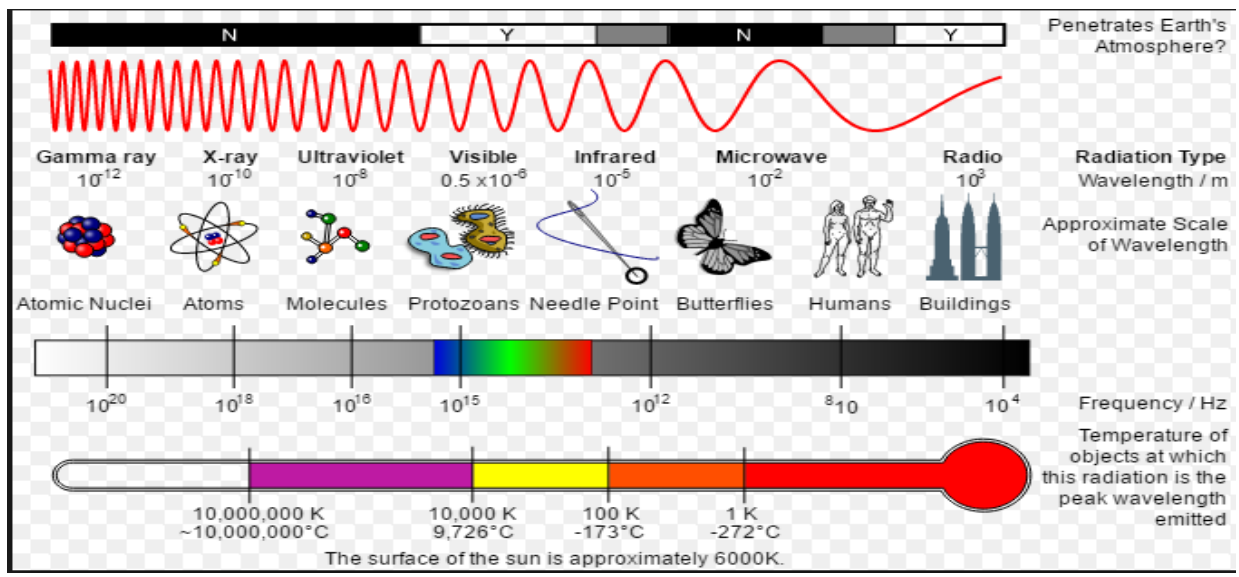

Fig:5 Electromagnetic spectrum.(stalling, 2009)

While High frequency signals are not used for communication but it has ability to carry huge amount of data.(stalling, 2009)

Figure 5 shows that visible and radio waves have the ability to penetrate on earth atmosphere. Gamma rays are extremely high frequency rays, which consists of high energy photon. A process of atomic nuclei decay called gamma decay which releases atomic energy. Atom is a good source of $\mathrm{x}$-rays. Different molecules are good source of UV; it has both harmful and beneficial effect on human life. Similarly, all different frequency ranges are use for different purpose.

\subsection{Communication between Infrared, Gamma and Electrons in Atmosphere}

Figure 6 depicts absorption of different type of solar radiation (X-rays to infrared rays) in the earth's atmosphere. U-V rays and X-rays are all ionized and absorbed in upper layers of atmosphere except visible and infrared light, which travel in troposphere (lower layer of atmosphere) (Mohanakumar, 2008)

In troposphere layer, propagation speed of radio waves in air is reduced as compared to the speed in vacuum. Greater the density of air keep slower the movement of wave and higher the refractive index. Troposphere helps to scatter EM radiation over long ranges on the earth. Short wavelength rays such as gamma and x-rays are unable to penetrate in lower layer of atmosphere, nitrogen and oxygen of this layer eliminate them. [13] As we seen from exosphere to troposphere from visible to infrared rays are absorbed in troposphere. $\mathrm{CO} 2$ and $\mathrm{H} 2 \mathrm{O}$ are good absorber of infrared rays. As we know, atoms have revolving electrons with different energy level, molecules of $\mathrm{CO} 2$ and $\mathrm{H} 2 \mathrm{O}$ are able to rotate or vibrate with unusual vibrational and rotational form with different energy in air. The difference in vibrational and rotational energy level of molecules is less than electrons in atom. As electron absorbs energy, it moves up to higher energy level. Wavelength of radiation and wave energy are converse to each other. Shorter the wavelength of radiation, high will be the wave energy. If energy level of molecule is less than atom, wavelengths emission or absorption by molecule is longer within infrared spectrum. These molecules absorb radiation within infrared spectrum. Therefore, we conclude that from visible light to radio waves portion of spectrum are able to communicate in troposphere (Marín, E., 2008) 

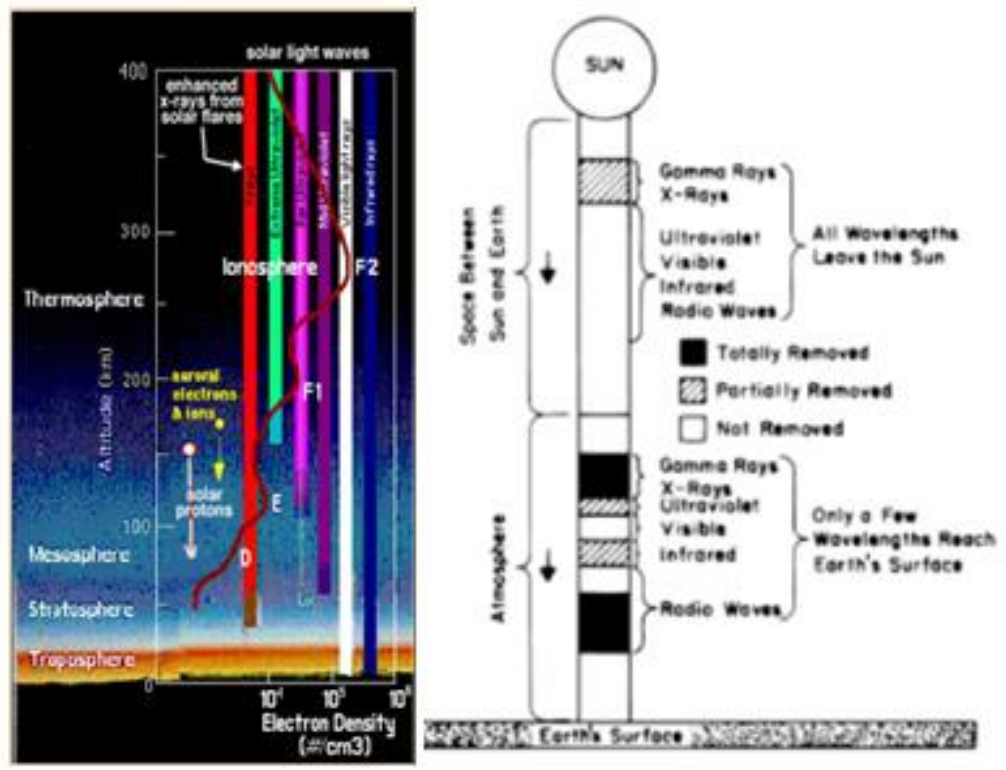

Fig:6 absorption of rays at different layers of atmosphere (Mohanakumar, 2008)

\subsection{Co-relation with Scriptures}

The behaviour of light includes absorption of transmission, reflection, refraction, scattering, diffraction, interference and polarization. When light strikes an object, energy is accounted within Transmission, absorption and reflection. Within transmission, light may be scattered, or may get refracted. Part of the light, which does not transmit neither reflect, gets absorbed and its energy is used as heat energy of the molecules for the absorbing material. The light is converted, when it traverse during such processes make us sight any objects. Light can also be polarized by reflection.

The Author suggests here that these ionized light particles are Angels. The behaviour of Angle is illustrated below in the context of Torah, Quran and Bible

All scriptures agreed upon angels' existence, Angels changing their shapes, Data can vary its forms too, Quran has illustrated Angels as Light which travel faster enough to be unseen to human eye. Within Torah, In Herbew, Mal'akh (מַלְֵֵ), is the word most often used for Angels, means "messenger" (cf. Ugaritic lak "to send").The Bible frequently calls the angel the mal'akh of God; yet the same title is occasionally applied to human agents of the Deity (Hag. 1:13; Mal. 2:7). Elsewhere angels are called 'elohim (usually "god" or "gods"; Gen. 6:2; Job 1:6), more often bene 'elohim or bene 'elim (lit. "sons of gods") - in the general sense of "divine beings." They are also known as kedoshim (qedoshim; "holy beings"; Ps. 89:8; Job 5:1).

Bible describe about existence of angel as "For by Him all things were created, both in the heavens and on earth, visible and invisible, whether thrones or dominions or rulers or authorities-all things have been created by Him and for Him. And He is before all things, and in Him all things hold together." (The truth about angelic beings)

Jesus declared that "a spirit hath not flesh and bones, as ye see me have" (Luke 24:37-39).

Bible declares about angel that they are localized mean they can be present at one place at a time.

"Angels are spirits rather than physical beings, they don't have to be visible at all" (Colossians 1:16).

So, Bible depicts Angel like a spirit and not be visible like human being but only in special conditions.

"Praise be to Allah, Who created (out of nothing) the heavens and the earth, Who made the angels, messengers with wings..." (Quran, 35,1 )

The Wings as narrated in the last mentioned Scripture means, Light, that is carrier and that is able to travel

\section{QUANTUM INTERNET}

This section is written keeping in view the communication between Angels i-e Light and, Light emitted from Humans 


\subsection{Biophoton Communication in Cell}

Biophoton pattern consist of short irregular periodicity bursts, it is said that bio photon are extraordinarily has resemblance with noisy channel which is used to send and receive binary data. This statement is quite useful to explain how cell can receive these low levels of radiation in noisy environment. It is considered that cell is a best source of biophoton but thinking behind it, many molecular reactions have ability to emit photons and it is transported to the cell by different energy carry excitation. Same process carries out by the photosynthesis, when energy transfers from photons across massive protein matrices. (MIT Technology Review, 2012)

\subsection{Communication of Angels to Humans: Internetworking of Photons}

Human body is a source of natural radiation (Toohey RE, Keane AT, Rundo J, 1983), human body contains radionuclide which radiates energy continuously. $40 \mathrm{~K}, 238 \mathrm{U}, 232 \mathrm{Th}, 14 \mathrm{C}, 87 \mathrm{Rb}$ and many other elements are source of radiation from human body, all these radiation moving in all direction around human body.

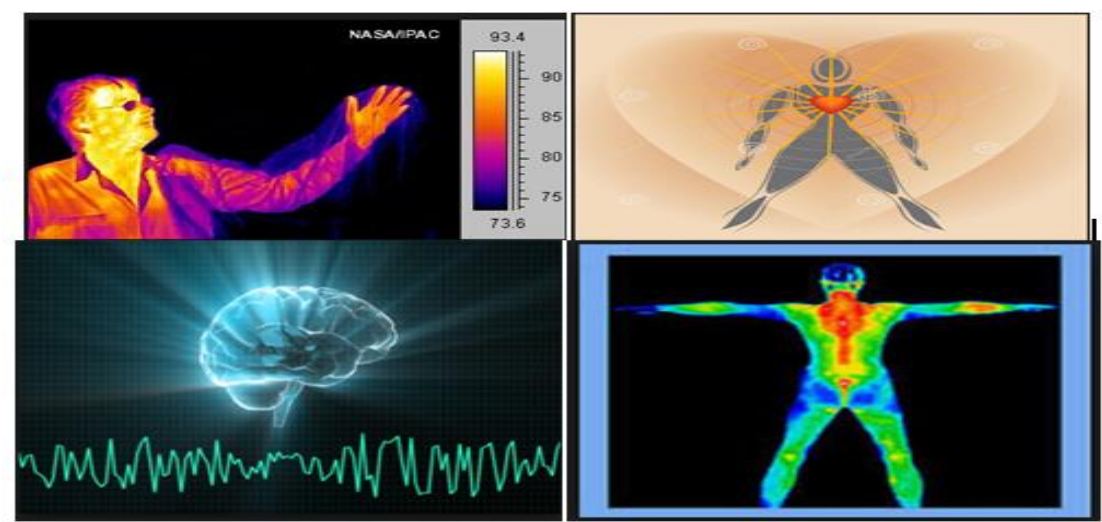

Fig: 7 Human body is natural source of radiation (Toohey RE, Keane AT, Rundo J, 1983)

Figure above shows much of the person body radiates as infrared light which is invisible for human being. High concentration of Polonium (210Po) element within skeleton of our body make it high source of radiation. Main mechanism through which our body naturally radiates as follows: The gamma rays produced by the radionuclide in environment interrelate with human body atom, it produces photoelectric effect. So, our bodies act as natural source of radiation.

\subsection{Co-Relation with Scriptures}

According to Torah, Lord bestowed Moses Ten Commandments and sent Angel. It is narrated as

"And now I am sending my angel to go before thee and guard the on the way and lead thee to the place I have made ready for thee" (Ex 23:20-21).

Genesis narrates about sighting of Angels by the Prophet Jacob, who dreamed and beheld a ladder fixed on the earth, whose top reached to heaven, and the angels of God ascended and descended on it (Gen. 28:12).

When Jacob departed Laban and returned home to Esau, he looked up and saw the host of God encamped; and the angels of God met him (Gen. 32:1).

The scripture that is send as last holy book, describes the particular situation when information about the conception of Jesus was shared with Mary and God sent Gabriel to Mary in the form of a man:

"...Then We sent to her Our angel, and he appeared before her as a man in all respects." (Quran 19:17)

This clearly narrates that the internet of communication existed between wave particles i-e Angels and that of radiation emitted from human bodies. In other words, communication was happening between bioPhotons and corpuscles at the time of narration of Scriptures. Humans and Interaction with Angels has been mentioned in scriptures. As mentioned in Section 3.0 where it's narrated, Praise for Allah ...Who made the angels, messengers with wings who can travel, the Philosophy of Scriptures is made understandable with emergence of science and vice versa i.e. receiver, sender, data carrier and a messenger

"There is no human being but has a protector over him (or her) (i.e. angels in charge of each human being guarding him, writing his good and bad deeds)."(Quran 86:4) 
Thus scripture has already informed about the existence of bio-photons centuries back, and since it has been narrated in same scripture as agreed by bible as torah, that Angels are Messengers, thus, the authors derive that every photon existing around a living human being is responsible for carrying his/her information and record of data until its life ends

As narrated in Quran, “...and He sends guardians (angels guarding and writing all of one's good and bad deeds) over you, until when death approaches one of you.."(Quran, 6:61)

"The heart is a sensory organ and acts as a sophisticated information encoding and processing centre that enables it to learn, remember, and make independent functional decisions,"[REF: (Rollin McCraty, 2003).

Human Heart is responsible to generates largest electromagnetic field with body which is measured in an electrocardiogram (ECG). It is scientifically proven that this electromagnetic field is 60 times greater in amplitude, than the waves which are emitted by human brain and are recorded as electroencephalogram (EEG).Research suggests that this electromagnetic field is powerful enough to be can be detected and measured several feet away from a person's body or when two individuals are found in close proximity. (Rollin McCraty, 1998)

Given the above facts, The relation of Angels in terms of sending messages to human's heart is narrated as follows, where Gabriel- An angel have been used convey the revelation from God to His human messengers.

"Gabriel - for he brings down the (revelation) to your heart by God's will..." (Quran 2:97)

\section{LOOP OF INFINITY}

Einstein Special Theory of Relativity( (Koks., 2014) narrated that any moving object measures shorter in its direction of motion, and can disappear if its velocity increases at the speed of light. scientists in the LIGO Scientific Collaboration, have experimented and have not only observed ripples of gravitational waves using specialised equipments on Earth. These waves are decoded and the particles insides waves could make scientist determine the source of these gravitational waves which according to their calculations were the result of a collision between two huge black holes, 1.3 billion light years away.

These signals were detected using Laser Interferometer Gravitational-wave Observatory (LIGO), in order to detect incredibly tiny vibrations from passing gravitational waves (Abramovici, A., Althouse et al, 1993). After obtaining the gravitational signals, these were converted into audio waves and could listen to the sound of two black holes spiralling together, and afterwards merging into a larger single black hole. How interesting it is to visualise these waves which have been rippled through the universe, and wrapped around the fabric of space-time. It just took them more than a billion years to be caught at earth and to get intercept using the faint traces of their former; collision based violent origins (Abbott et.al, 2016).

\subsection{Co-relation with Scriptures}

Gravitational Force and Discovery of Real Internet of Things since 1.3 Billion years has proved that data never dies. Parallel world existence is a truth that is covering the suspicious existence of mankind since billion of years and with the evidences narrated by Nargis Mavalvala at MIT, it is understood that all kind of activities and data, sounds and actions are saved in waves. Photons carry this data from infinity to infinity and derivation of these data can lead to the origin of other world which actually is existing but has just changed its form from solid substances to waves like recorded particles, absorbed in ionized photons. Science has proved that data stays forever. Scriptures already have said that Data of world is saved and reconciliation not only is possible but will be done as well. Day of judgement is day of reconciliation data

\section{CONCLUSION}

Parallel world existence is a truth that is covering the suspicious existence of mankind since billions of years and with the evidences narrated in this paper, it is understood that all kind of activities and data, sounds and actions are saved in waves. Photons carry this data from infinity to infinity and derivation of these data can lead to the origin of other world which exists but in different form of substance. Solid substances can transform to waves-like recorded particles, which can be absorbed in ionized photons. Science has proved that data stays forever. Scriptures already have said that Data of world is saved and Angels are messengers to record data of every living being and keeps it safe until infinity. Former Scriptures like Torah \& Bible also have narrated Angels as Messenger, whereas Last scripture has given verdicts that these messengers or Angels are actually "Light" i.e Photon, by exhibiting properties of these Angels in various verses duly mentioned in this research paper. The paper also has well discussed Bio-Photons and in scientific reasoning to studies, it is also proved that data from humans are able to be recorded by these Angels, I-e Photons, in the form of Quantum internet of things and also from Angels to Angels in form of Quantum Intranet which is 
also correlated with scriptures and scientifically validated in this research. Author has derived a strange yet interesting aspect, while making this correlation of study that the knowledge given in scriptures, thousands of years back is still a quest of science. Angels as messenger are responsible to record, carry, and keep this data safe till infinity of time until the reconciliation of data will be done. Scriptures narrate that a final Day of Judgment is actually day of reconciliation of data.

\section{REFERENCE LIST}

Marín, E. (2008). True/untrue explanations in Physics: Lat. Am. J. Phys. Educ, 2 (3).

Hoffmann, D. (2009). Planck's Constant h. In Compendium of Quantum Physics (pp. 478-480). Springer Berlin Heidelberg.

Computing fundamentals (2016, May 20) retrieved from http://whatis.techtarget.com/definition/quantum

Dutton, H. J. (1998). Understanding Optical Communications. united state: IBM Corporation, International Technical Support Organization.

Huray, P. G. (2009). Maxwell's Equations. Wiley-IEEE Press.

Einstein for membership in the Royal Prussian Academy of Science-Theory of Quanta, (2016, May 20) retrieved from https://en.wikipedia.org/wiki/Prussian Academy of Sciences

Introduction to faith of Islam (2016, May 20) retrived from http://www.slideshare.net/SahrilGani/anintroduction-to-the-faith-of-islam-51606038

Rollin McCraty, P. M. (1998). The Electricity of Touch: Detection and Measurement of Cardiac Energy Exchange Between People. Karl H. Pribram, ed. Brain and Values: Is a Biological Science of Values Possible. Mahwah, NJ: Lawrence Erlbaum Associates.

Koks., D. (2014). Physics. Retrieved 5 20, 2016, from math.ucr.edu: http://math.ucr.edu/home/baez/physics/Relativity/SpeedOfLight/speed_of_light.html

Toohey RE, Keane AT, Rundo J. Measurement techniques for radium and the actinides in man at the Center for Human Radiobiology. Health Phys,44(1):323-341; 1983.

MIT Technology Review. (2012, May 22). Retrieved 5 2016, 20, from technologyreview.com: https://www.technologyreview.com/s/427982/biophoton-communication-can-cells-talk-using-light/

Mohanakumar, K. (2008). Stratosphere Troposphere Interactions: An Introduction. Springer Science \& Business Media. (Stalling, 2009)

Stalling, W. (2009). Data and Computer Communications. india: Dorling kindersly.

Close, F. (2011). The Infinity Puzzle: Quantum Field Theory and the Hunt for an Orderly Universe. Tantor Audio

The truth about angelic beings. (n.d.). Retrieved 5 20, 2016, from Christiananswer.net.

Abramovici, A., Althouse, W. E., Drever, R. W., Gürsel, Y., Kawamura, S., Raab, F. J.,... \& Vogt, R. E. (1992). LIGO: The laser interferometer gravitational-wave observatory. Science, 256(5055), 325-333.

J. Ko, I.-Y. K.-T.-Y. (2016). Analysis and control of the photon beam position. Journal of syncroton, 448-454.

Abbott, B. P., R. Abbott, T.D. Abbott, M. R. Abernathy, F. Acernese, K. Ackley, C. Adams, et al. "Observation of Gravitational Waves from a Binary Black Hole Merger.” Physical Review Letters 116, no. 6 (February 11, 2016).

Scriptures: Torah, Bible, Quran 